Case Report

\title{
A Case of Adrenal Metastasis in Seminoma
}

\author{
Bouabdallah Zakaria, ${ }^{1}$ Théveniaud Pierre-Etienne,, ${ }^{1}$ Duchatelle Véronique, ${ }^{2}$ \\ Molinié Vincent, ${ }^{2}$ Massoud Walid, ${ }^{1}$ and Baumert Hervé ${ }^{1}$ \\ ${ }^{1}$ Department of Urology, Paris Saint Joseph Hospital Group, 185 Rue Raymond Losserand, \\ 75014 Paris, France \\ ${ }^{2}$ Department of Pathology, Paris Saint Joseph Hospital Group, 185 Rue Raymond Losserand, \\ 75014 Paris, France
}

Correspondence should be addressed to Bouabdallah Zakaria; bouabdallahz@hotmail.fr

Received 15 May 2013; Accepted 15 June 2013

Academic Editors: J. P. Gearhart, C. Liao, and F. M. Solivetti

Copyright (C) 2013 Bouabdallah Zakaria et al. This is an open access article distributed under the Creative Commons Attribution License, which permits unrestricted use, distribution, and reproduction in any medium, provided the original work is properly cited.

We report an uncommon case of testicular cancer with adrenal metastasis without retroperitoneal or distant metastatic disease. This situation is highly unusual. In fact, no similar case was reported in the literature. Our case is the first adrenalectomy that has been performed for secondary localization of testicular cancer. After eighteen-month followup, the patient was doing well, with no evidence of disease.

\section{Case}

A 53-year-old patient underwent a right radical orchiectomy after he noted a testicular mass on self-examination. Pathology revealed a testicular seminoma. He received 3 cycles of bleomycin, etoposide, and cisplatin associated with radiotherapy of iliac and retroperitoneal lymph nodes. Five years later, he presented a contralateral seminoma, which was treated by radical orchiectomy and 4 cycles of etoposide and cisplatin. A CT scan Nine years later showed a mass of the right adrenal gland with fixation at PET scan associated with a preaortic lymph node fixation. Tumor markers were negative (alpha-fetoprotein and beta-human chorionic gonadotrophin). No evidence was found for other distant metastases. A right adrenalectomy with lymph node dissection was performed by laparoscopy. Pathologic examination showed an adrenal metastasis of a testicular seminoma without lymph node metastasis (Figures 1, 2, and 3). The patient is disease free at last followup 18 months after surgery.

\section{Comment}

Testicular cancer is the first solid tumor in young men between 20 and 30 years old [1]. Seminoma has a high metastatic capacity. Metastases initially occur in the retroperitoneal nodes before additional systemic involvement [2]. The most common metastatic sites of germinal tumors are the lungs, liver, central nervous system, and bone [2, 3]. Other localizations are atypical. Cases of isolated metastases were reported in the literature: spleen, skin, prostate [4-6], and so forth. Isolated adrenal metastasis of seminoma is uncommon, and, to our knowledge, this is the first case reported. PET scan can help diagnose difficult cases [7]. The treatment of metastasis is based on chemotherapy. However, surgery may be indicated in the following cases: diagnostic doubt, functional repercussion, or residual mass $[3]$. 


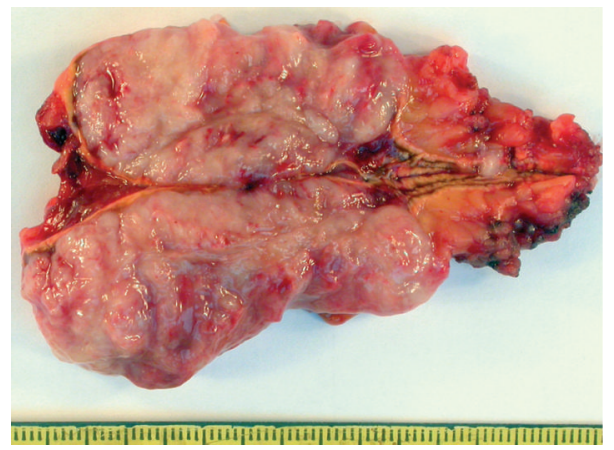

FIGURE 1: Macroscopic aspect of the tumor.

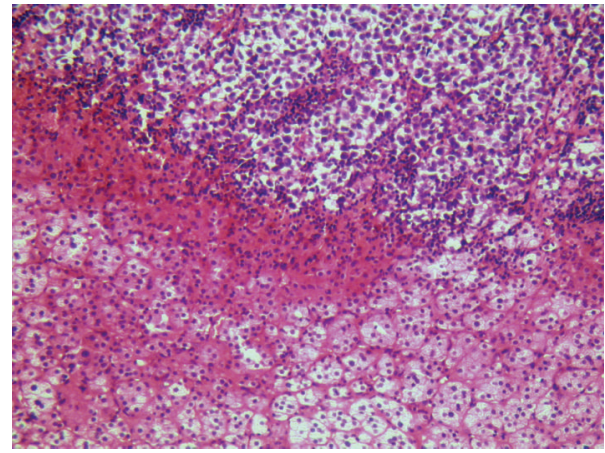

FIGURE 2: Standard coloration with hematoxylin and eosin showing both tumor and normal adrenal glands $(\times 20)$.

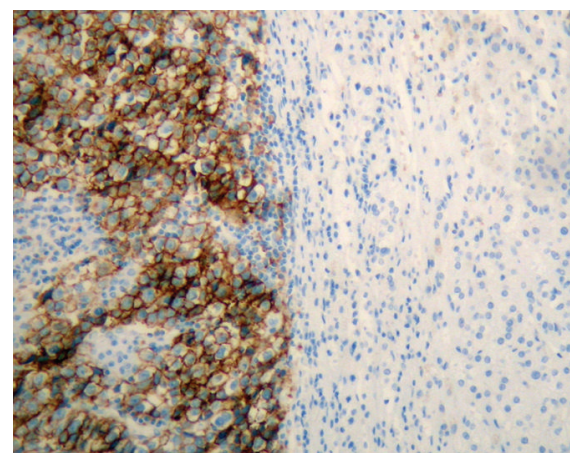

(a)

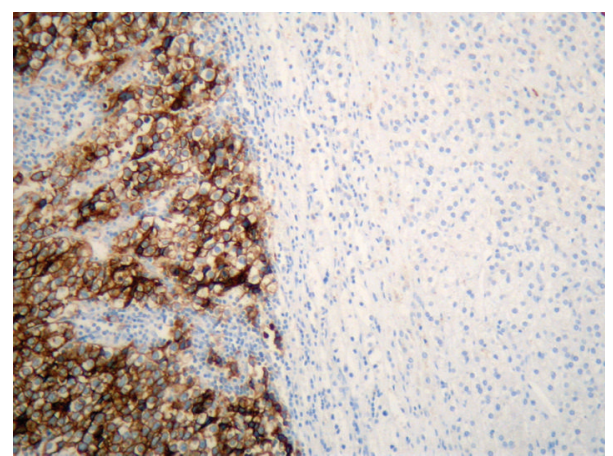

(b)

Figure 3: Seminoma cells markers expression (a) CD 117 and (b) PLAP.

\section{References}

[1] V. Cortessis, "Epidemiologic insights into the occurrence and causes of testicular cancer," in Germ Cell Tumors, D. Raghavan, Ed., pp. 16-29, BC Decker, London, UK, 2003.

[2] M. M. Nguyen, A. S. Corr, and C. P. Evans, "Testicular cancer metastatic exclusively to the brain and spleen," Urology, vol. 63, no. 1, pp. 176-178, 2004.

[3] Y. Neuzillet, A. Méjean, and T. Lebret, "Rare locations of metastases from germ cell cancers," Progres en Urologie, vol. 18, no. 7, pp. S388-S391, 2008.

[4] A. M. Moore, S. R. Simon, and L. H. Einhorn, "A case of relapsed testicular cancer initially isolated to the spleen," American Journal of Clinical Oncology, vol. 32, no. 6, article 639, 2009.

[5] H. Tazi, M. Badraoui, S. Qasmi, and B. Hassam, "Metastatic pure testicular seminoma of the skin," Progres en Urologie, vol. 21, no. 1, pp. 76-78, 2011.

[6] S. B. Farnham, S. E. Mason, and J. A. Smith Jr., "Metastatic testicular seminoma to the prostate," Urology, vol. 66, no. 1, p. 195, 2005.

[7] J.-Rioja, M. Rodríguez-Fraile, R. Lima-Favaretto et al., "Role of positron emission tomography in urological oncology," $B J U$ International, vol. 106, no. 11, pp. 1578-1593, 2010. 


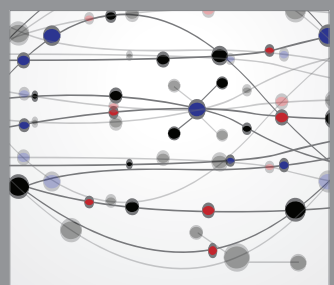

The Scientific World Journal
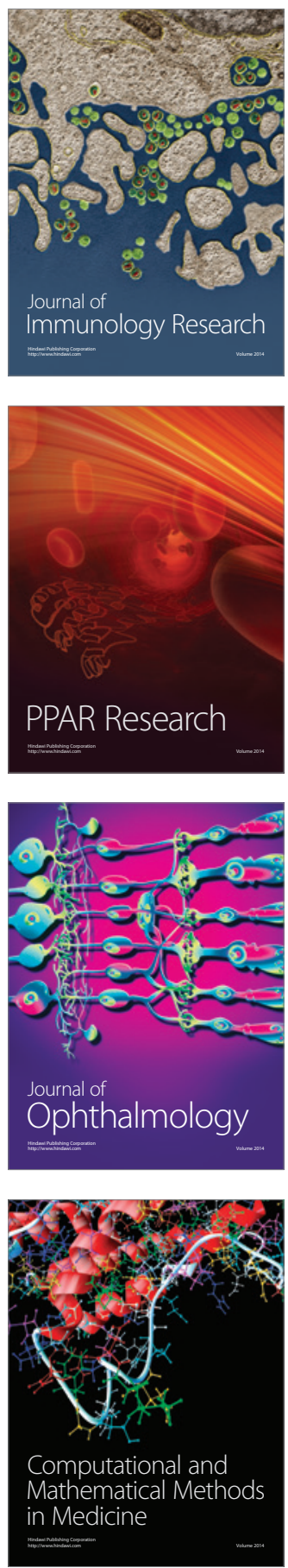

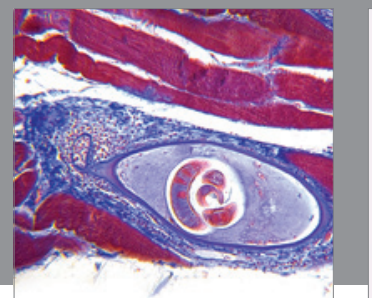

Gastroenterology

Research and Practice
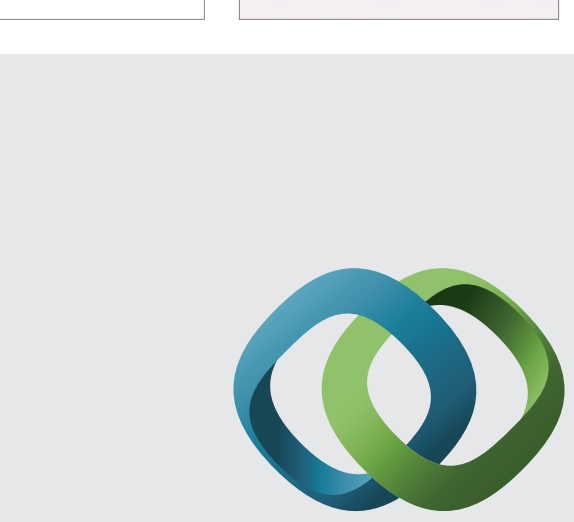

\section{Hindawi}

Submit your manuscripts at

http://www.hindawi.com
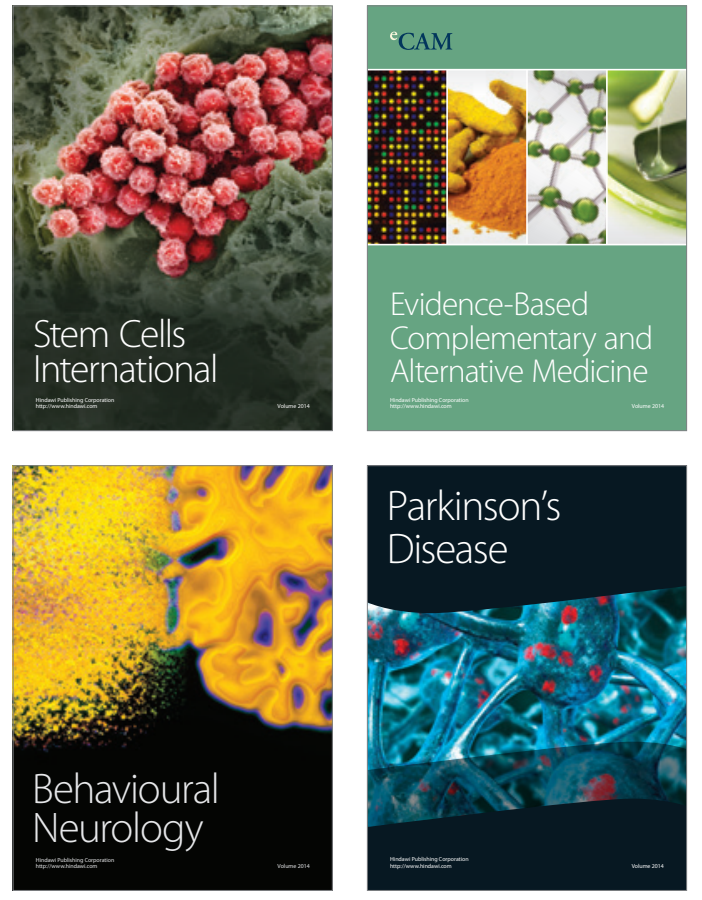
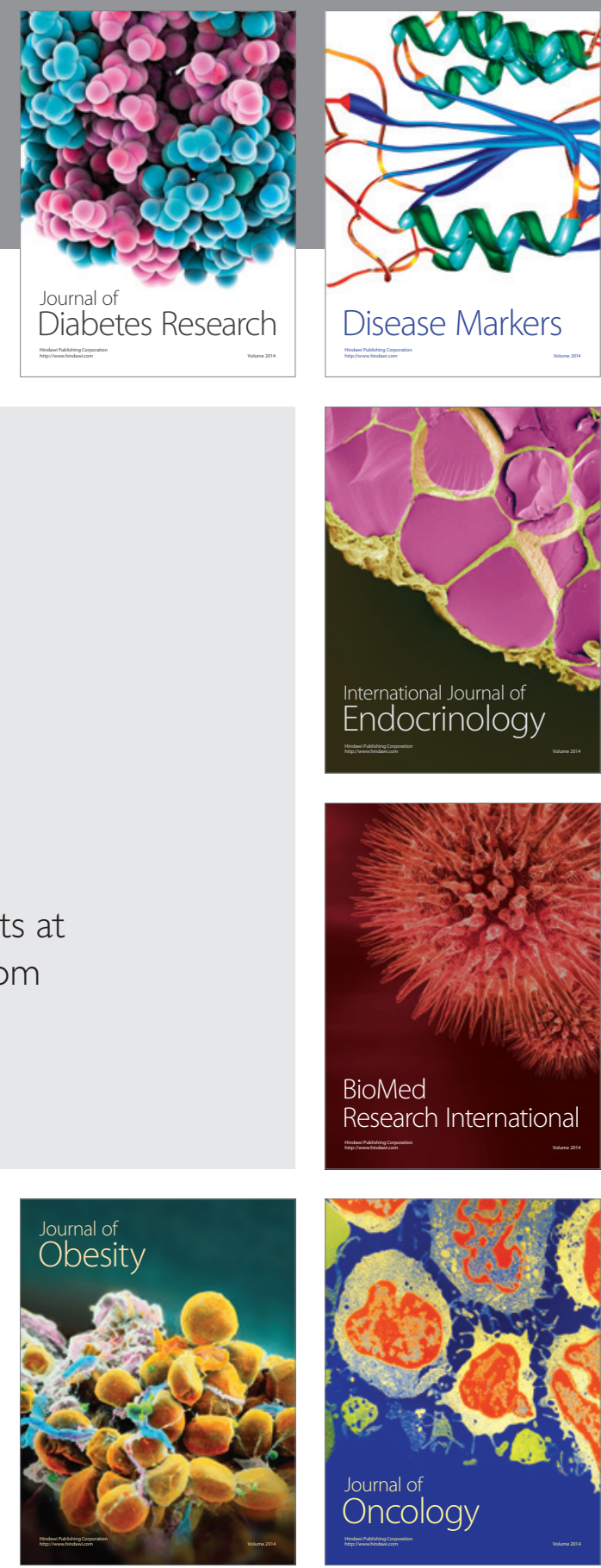

Disease Markers
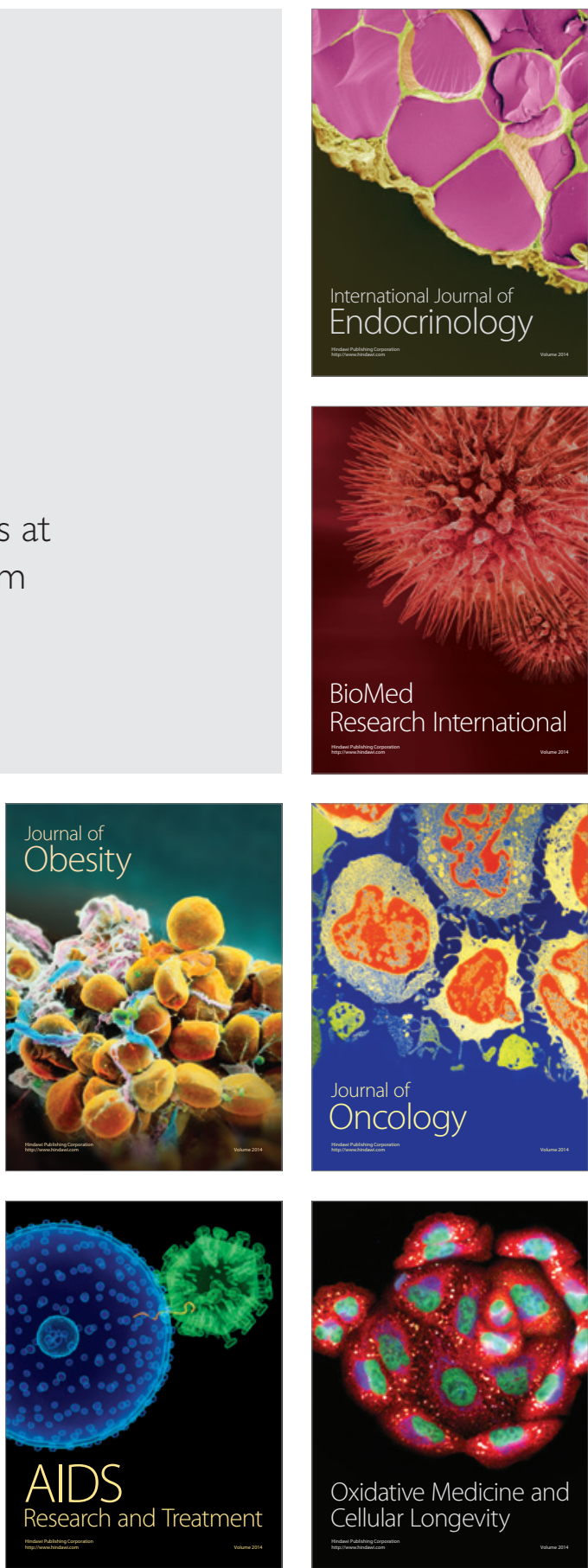